Cómo citar este artículo en Chicago: Arévalo Viveros, Luis Fernando. "Negación de la identidad discursiva, violencia y criminalidad: aproximación semiótica e interdisciplinaria”. Escritos 29, no. 63 (2021): 307-325. doi: http://doi.org/10.18566/

\title{
Negación de la identidad discursiva, violencia y criminalidad: aproximación semiótica e interdisciplinaria
}

\author{
Denial of discursive identity, violence and criminality: Semiotic and \\ interdisciplinary approach
}

\author{
Luis Fernando Arévalo Viveros
}

\begin{abstract}
RESUMEN
Este artículo expone los resultados y conclusiones de una investigación orientada a analizar la incidencia de los discursos propios y ajenos en la configuración identitaria de sujetos criminales colombianos, enunciados en la literatura de Mario Mendoza y en otras narrativas académicas y periodísticas. Asimismo, se estudiaron las identidades como signos discursivos y se aportó una explicación sobre la violencia y la criminalidad como manifestaciones de la negación de las identidades de los delincuentes y de la ruptura del principio de regulación del discurso. El estudio, basado en la perspectiva teórica, metodológica e interdisciplinaria de la escuela semiótica de París, evidenció que el actuar violento y criminal de los sujetos analizados es orientado por una forma de vida y un esquema narrativo que implica una configuración determinada de las identidades discursivas, el encuentro con un yo-sí mismo y otros que se niegan, manifestaciones disfóricas constantes e intensas, estados de sinsentido y sin sentido movilizadores de la destrucción de los otros como representaciones de un sí mismo inaceptable, que se intenta resignificar y restaurar con una violencia compensadora. De esta manera, el estudio busca aportar a la comprensión de la criminalidad en Colombia y sus múltiples causas.
\end{abstract}

Palabras clave: Identidad discursiva; Negación; Violencia; Criminalidad; Semiótica; Mario Mendoza.

\section{ABSTRACT}

This article presents the results and conclusions of a research study aimed at analyzing the incidence of Colombian criminals' discourses and other people's discourses in the configuration of the criminals' identity, as enunciated

1 Profesor titular Escuela de Idiomas, Universidad Industrial de Santander, Colombia. Doctorat en Langues, Littérature et Civilisations Romanes. Magíster en Lingüística y Español. Especialista en Pedagogía de la Lectura y la Escritura. Licenciado en Lenguas Modernas, inglés - francés. Correo electrónico: lufareva@uis.edu.co. 
in the works of the Colombian author Mario Mendoza and other academic and journalistic narratives. Likewise, identities were studied as discursive signs constructed from social relations; and an explanation was provided for violence and criminality as manifestations of the criminals' denial of their identities and the rupture of the principle of discourse regulation. The study is based on the theoretical, methodological and interdisciplinary perspective of the Semiotics School of París. It showed that the violent and criminal behavior of the analyzed subjects is guided by a way of life and a narrative scheme that implies a specific configuration of discursive identities. This also involves the encounter with a self - oneself and others who are denied-, constant and intense dysphoric manifestations, states of nonsense and senseless that mobilize the destruction of others as representations of an unacceptable self, which tries to resignify and restore with a compensatory violence. In this way, the study seeks to contribute to the understanding of crime in Colombia and its multiple causes.

Keywords: Discursive Identity; Denial; Violence; Criminality; Semiotics; Mario Mendoza.

La estructura del habla va a ser la misma estructura del sujeto [...] El lenguaje se inserta en esta estructura como el gran mediador entre el sujeto y la sociedad, como el gran mediador también entre las diferentes estructuras del sujeto. ${ }^{2}$

\section{Introducción}

$\mathrm{L}$ a acción violenta y criminal, que fractura y se opone a los valores positivos de una cultura, siempre genera múltiples inquietudes, desafíos para el pensamiento en variados campos del conocimiento, entre ellos, las ciencias humanas, sociales y las artes. Los interrogantes no solo se centran en el "quién" o sujeto de hacer del crimen y en el "cómo" actuó, sino, ante todo, en el "por qué" de la acción criminal, es decir, en aquello que impulsa el crimen. A propósito, las razones de las acciones violentas y criminales pueden ser diversas y complejas, por ello, la trascendencia de observar el problema desde perspectivas interdisciplinarias como la semiótica.

A partir de lo anterior, en este artículo se planteó la pregunta ¿cómo en la trilogía de novelas Scorpio City (1998), Relato de un asesino (2001) y Satanás (2002), de Mario Mendoza, la negación de la identidad de los criminales es un proceso de construcción discursiva que conduce a la destrucción de otros como representaciones de un yo que se rechaza? Sobre el corpus literario seleccionado para estudiar la relación entre la negación de la identidad discursiva, la violencia y la criminalidad, es preciso considerar que la literatura a través del universo de relatos artísticos ha descrito con precisión y ha sugerido diversas hipótesis sobre los impulsos humanos que movilizan acciones nobles y abyectas. Acerca de estas últimas, se pueden recordar obras universales como el Corazón delator (1843), de Edgar Allan Poe; Crimen y castigo (1866) de Fedor Dostoievski, o El extraño caso del doctor Jekyll y mister Hyde (1886), de Louis Stevenson, entre muchas otras. La literatura colombiana no ha sido ajena a la inquietud por la acción criminal, problema que en cada entorno social y cultural puede tener orígenes y configuraciones diferentes; por esto, para la investigación, se seleccionaron las novelas citadas de Mendoza, además, la trilogía se basa en la masacre perpetrada por Campo Elías Delgado Morales en el restaurante Pozzetto de Bogotá, en 1986.

Ahora bien, para ampliar los resultados de la investigación, que tuvo como objetivos analizar la incidencia de los discursos propios y ajenos en la configuración identitaria de sujetos criminales, estudiar

2 José Antonio Marina, La selva del lenguaje (Barcelona: Anagrama, 1998), 108. 
sus identidades como signos discursivos y explicar la violencia y la criminalidad como manifestaciones de la ruptura del principio de regulación del discurso en los criminales debido a la negación de sus identidades, en este artículo se comparan los casos analizados en el corpus literario con los estudiados por el antropólogo Esteban Cruz Niño, en la obra Los monstruos en Colombia sí existen (2013) y con narrativas de criminales enunciadas en medios masivos de información nacionales.

Cabe anotar que, tanto en los casos literarios como en los documentados por Cruz y los medios, la construcción discursiva de las identidades de los criminales y la negación de estas instauran la violencia como una forma de vida que moviliza acciones o programas narrativos transgresores de las leyes. Los crímenes son orientados por un esquema narrativo o programa de acción recurrente en los entornos culturales enunciados en las historias ficcionales y reales, esquema que puede ser representado de la siguiente forma:

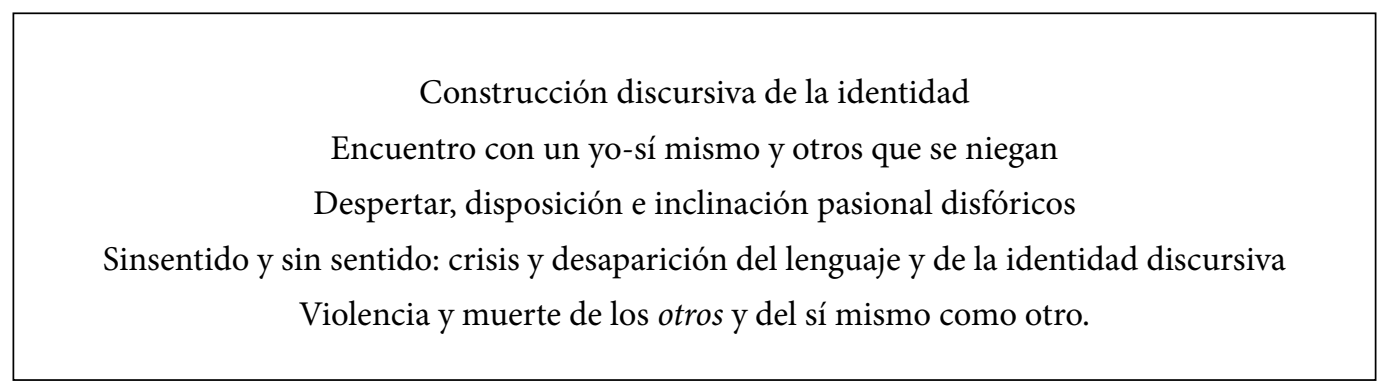

Cuadro 1. Esquema de negación de la identidad discursiva y violencia criminal. ${ }^{3}$

De forma ulterior, los resultados evidenciarán el desenlace de cada uno de los componentes del esquema expuesto, no sin antes proponer la identidad discursiva de un sujeto o de un colectivo social, punto de partida de este ejercicio interpretativo, como un constructo complejo y multidimensional de lenguaje, erigido en interacciones sociales y dinámicas enunciativas que producen un sentido de identidad como efecto de permanencia. ${ }^{4}$ En otras palabras, tomando distancia de enfoques subjetivistas u objetivistas del concepto, la identidad discursiva es el sentido que el sujeto o grupo social construye de sí mismo y de los

3 Luis Fernando Arévalo Viveros, "Négation de l'identité et destruction de l'autre dans Scorpio City (1998), Relato de un asesino (2002) et Satanás (2002) de Mario Mendoza (Colombie, 1964)” (tesis doctorado, Université d’Aix Marseille, 2019), 320.

4 Esta postura teórica sobre la identidad se basa en las propuestas de Algirdas Julius Greimas y Paul Ricoeur. La primera sugiere que "la identidad sirve, igualmente, para designar el principio de permanencia que permite al individuo permanecer el 'mismo,' 'persistir en su ser' a lo largo de su existencia narrativa, a pesar de los cambios que provoca o sufre”. Algirdas Greimas y Joseph Courtés, Semiótica: Diccionario razonado de la teoría del lenguaje. Volumen 1 (Madrid: Gredos, 1990), 213. La segunda propone el concepto de identidad narrativa que se amplía a identidad discursiva. Al respecto, Paul Ricœur expresa: "El frágil vástago, fruto de la unión de la historia y de la ficción, es la asignación a un individuo o a una comunidad de una identidad específica que podemos llamar su identidad narrativa [...] la propia identidad del quién no es más que una identidad narrativa”. Tiempo y narración. Vol. 3: El tiempo narrado (México: Siglo XXI, 2003), 997. 
otros para sí mismo y para los demás, y que el entorno social hace del sujeto y de otros conjuntos humanos. Desde esta perspectiva, la identidad discursiva depende de la alteridad, es individual y social, se transforma y conserva, es diacrónica y sincrónica, es armónica e inarmónica, dinámicas de significación contrarias, contradictorias y complementarias que rigen su multidimensionalidad, compuesta por el cuerpo, un carácter, las representaciones sociales y la cultura; dimensiones percibidas comúnmente como identidades, que rigen constituyentes identitarios como la cognición, la axiología, las pasiones y los sistemas de significación, entre ellos, la lengua, los gestos, los vestuarios y otros.

Cabe aclarar que la mención fragmentada de cada una de las dimensiones y constituyentes identitarios, como si existieran fronteras definidas entre ellos, solo obedece al ejercicio teórico y metodológico de comprensión de la identidad discursiva, pues, como bien lo afirma Clifford Geertz, se hace extraordinariamente difícil trazar una línea entre lo que es natural, universal y constante en el hombre y lo que es convencional, local y variable. En realidad, trazar semejante línea es falsear la situación humana o, por lo menos, representarla seriamente mal. ${ }^{5}$

La dimensión corporal de la identidad, localizada en un espacio y espacio en sí misma afectada por el tiempo es de orden discursivo y no discursivo. En tanto incluye las características físicas y biológicas de un cuerpo-actante que hace parte del mundo natural, este continuum o materia, ${ }^{6}$ al ser experimentada por el mismo sujeto y por la sociedad que la rodea, es semiotizada con y a través del discurso para generar imágenes o proyecciones de la masa corporal y de las ajenas. Se coincide así con la propuesta de Fontanille, quien distingue la carne del cuerpo propio:

La carne es la instancia enunciante en cuanto principio de resistencia/impulso material, pero también en cuanto posición de referencia, conjunto material que ocupa una posición de la extensión, a partir de la cual se organiza dicha extensión. La carne es al mismo tiempo la sede del núcleo sensoriomotor de la experiencia semiótica. Por otro lado, está el cuerpo propio, es decir, aquello que se constituye en la semiósis [...]. El cuerpo propio es el portador de la identidad en construcción y en devenir. ${ }^{7}$

La dimensión del carácter ${ }^{8}$ se entiende como "el conjunto de signos distintivos que permiten identificar de nuevo a un individuo humano como siendo el mismo [...]. El carácter, diría yo hoy, designa el conjunto de disposiciones duraderas en las que reconocemos a una persona". En consecuencia, el carácter es un signo generador y regulador, en gran parte, del efecto de continuidad o "principio de permanencia en el tiempo", que diferencia e identifica al sujeto o a un colectivo social de otro. Con tal regulación, el sujeto y quienes lo identifican instituyen, por medio del discurso, una historia encargada de mantener la memoria

5 Clifford Geertz, La interpretación culturas (Barcelona: Gedisa, 1989), 55

6 El continuum, o materia del contenido, sería todo lo que es pensable y clasificable. Umberto Eco, Decir casi lo mismo: Experiencias de traducción (Barcelona: Lumen, 2008), 49. Como materia, "mi cuerpo se cuenta entre las cosas, es una de ellas, está prendido en el tejido del mundo, y su cohesión es la de una cosa". Maurice Merleau-Ponty, El ojo y el espíritu (Madrid: Trotta, 2013), 22. El cuerpo humano como materia y presencia es experimentado, significado, identificado y clasificado en genotipos, fenotipos, etnias, estratos, culturas, etc., en general, en individuos y grupos identitarios, según el interés ideológico de quienes lo perciben y otorgan sentido.

7 Jacques Fontanille, Soma y sema: Figuras semióticas del cuerpo (Lima: Universidad de Lima, 2008), 33.

8 Desde su etimología, el término carácter remite a hacer marcas, signos grabados o fijos.

9 Paul Ricœur, Sí mismo como otro (México: Siglo XXI, 1996), 113, 115. 
sobre el ser y el hacer del sujeto, defendiendo su identidad a través de signos con efecto de permanencia como la condición humana, el nombre, los estados psicológicos y afectivos, los movimientos corporales y las acciones recurrentes. ${ }^{10}$ En ese sentido, "nuestras historias nos distinguen y nos hacen insustituibles". ${ }^{11} \mathrm{La}$ influencia del carácter es tan significativa en la identidad discursiva del sujeto, por ende, en las costumbres e identificaciones adquiridas, que se instala y somatiza o manifiesta en su dimensión corporal.

Es preciso insistir en que no se postula el carácter como una construcción discursiva totalmente invariable, sino como un complejo sígnico que produce un efecto de estabilidad a través de identificaciones focalizadas, recuerdos y costumbres. Sin embargo, no se puede omitir que ese efecto (principio de permanencia), en gran parte, deja tácitas las transformaciones a lo largo del tiempo de todas las dimensiones de la identidad discursiva del sujeto; así lo sugiere Ricœur: "La costumbre proporciona una historia al carácter; pero es una historia en la que la sedimentación tiende a recubrir y, en último término, a abolir la innovación que la ha precedido." ${ }^{2}$

A partir de lo anterior, emerge la pregunta: ¿de dónde surgen las identificaciones adquiridas y las costumbres propias de la dimensión del carácter? A esta es posible responder que la dimensión cultural de la identidad discursiva es una fuente encargada de determinar o manipular tanto el carácter como el mismo cuerpo del sujeto porque

somos animales incompletos o inconclusos que nos completamos o terminamos por obra de la cultura, y no por obra de la cultura en general sino por formas en alto grado particulares de ella: la forma dobuana y la forma javanesa, la forma hopi y la forma italiana, la forma de las clases superiores y la de las clases inferiores, la forma académica y la forma comercial. ${ }^{13}$

En suma, la dimensión cultural también da forma a la identidad discursiva. Esta dimensión, proveniente de la pertenencia del sujeto a una sociedad y a un entorno geográfico, es el conjunto de valores, significaciones del mundo, prácticas del sujeto y de los grupos humanos que funciona como una interfaz de conexión entre el cuerpo del sujeto, su carácter y prácticas sociales, dimensiones de la identidad discursiva en las que se manifiesta y hace explícita la cultura. En consecuencia,

vivimos, como un autor lo formuló claramente, en una "brecha de información". Entre lo que nuestro cuerpo nos dice y lo que tenemos que saber para funcionar hay un vacío que debemos llenar nosotros mismos, y lo llenamos con información (o desinformación) suministrada por nuestra cultura. La frontera entre lo que está innatamente controlado y lo que está culturalmente controlado en la conducta humana es una línea mal definida y fluctuante. ${ }^{14}$

10 No solo el sujeto enunciador manifiesta "yo soy, hago, tengo" para referirse a su carácter, quienes lo identifican expresarán "él o ella es, hace o tiene", naturalizando, atribuyendo esencia y destinando al sujeto, a través del discurso, a un carácter. Lo anterior es denominado por Ricœur identificaciones adquiridas, "por las cuales lo otro entra en composición de lo mismo. En efecto, en gran parte de identidad de una persona, de una comunidad, está hecha de estas identificaciones-con valores, normas, ideales, modelos, héroes, en los que la persona, la comunidad, se reconocen". Sí mismo como otro, 116.

11 Ricœur, Sí mismo como otro, 111, 134.

12 Sí mismo como otro, 116.

13 Geertz, La interpretación culturas, 55.

14 Geertz, La interpretación culturas, 55. 
Debido a esta omnipresencia oscilante de la dimensión cultural en la identidad discursiva, se producen efectos de permanencia o de diversidad de los sujetos. Sobre esta diversidad, de forma paradójica, cuerpo, carácter, sociedad y cultura imponen convenciones y formas de actuar en las diversas situaciones de interacción social, que provocan que la identidad discursiva también sea acto, acontecimiento en el que se actualiza la historia del sujeto, configuración sincrónica en la que la dimensión social de la identidad pareciera desprender al actor de lo que este y los otros evalúan como su propia identidad. El cuerpo investido de un carácter y una cultura se relaciona e inter-actúa con otros debiendo adaptarse, por pertinencia y regulación del lenguaje, a los espacios, los tiempos, las circunstancias y los roles que la vida social y cultural y el lenguaje exigen.

Por las situaciones de interacción, intencionalidades y cultura del sujeto, la dimensión de las representaciones sociales de la identidad discursiva es también cambiante, estratégica y circunstancial, y produce un efecto de multiplicidad o de facetas del sujeto. Sobre estas adaptaciones, Goffman manifiesta:

Dividimos al individuo, por implicación, de acuerdo con dos papeles básicos: fue considerado como actuante - un inquieto forjador de impresiones, empeñado en la harto humana tarea de poner en escena una actuación-y como personaje - una figura (por lo general agradable) cuyo espíritu, fortaleza y otras cualidades preciosas deben ser evocadas por la actuación. [...] concebimos el "sí mismo" representado como un tipo de imagen, por lo general estimable, que el individuo intenta efectivamente que le atribuyan los demás cuando está en escena y actúa conforme a su personaje. ${ }^{15}$

Cabe aclarar que la interacción en esta dimensión social de la identidad discursiva, desde una perspectiva dialógica, no la reducimos al contacto de dos o más cuerpos físicos y caracteres, sino que se amplía a la interacción del sujeto consigo mismo; se concibe entonces que el sí mismo del sujeto funciona como otro, un personaje representado, simulacro o enunciador, incluso, para el mismo sujeto. Hay que ver en sí mismo a otro, afirma Bajtín, y añade: "Una vivencia interna y una totalidad interna pueden vivirse concretamente (percibirse internamente) o dentro de la categoría yo-para-mí, o bien dentro de la categoría otro-para-mí, es decir, ora como mi vivencia, ora como la vivencia de este otro determinado y único". ${ }^{16}$ Las cuatro dimensiones citadas modalizan de forma permanente los constituyentes de la identidad discursiva: la cognición o el saber, la axiología o los sistemas de valores, las pasiones como estados afectivos y los sistemas de significación y expresión. Con esta ubicación teórica, desde una perspectiva semiótica de la identidad discursiva, se explica el proceso analítico para establecer la relación entre la negación de la identidad discursiva, la violencia y la criminalidad.

\section{Metodología}

El corpus de la investigación estuvo constituido por la trilogía de novelas Scorpio City, Relato de un asesino y Satanás, seleccionado por su relación directa con el objeto semiótico de estudio, esquematizado en el cuadro 1. Además, para ampliar los resultados, en este artículo el análisis incluyó discursos documentados

15 Erving Goffman, La representación de la persona en la vida cotidiana (Buenos Aires: Amorrortu, 1997$), 268$.

16 Mijaíl Bajtín, Estética de la creación verbal (México: Siglo XXI, 1982), 23, 29. 
en la investigación Los monstruos en Colombia sí existen y narrativas de medios masivos de información del país, y así se relaciona un conjunto de textos de la cultura que da cuenta de una problema como el vínculo entre la negación de la identidad discursiva, la violencia y la criminalidad en Colombia.

La teoría y el método de investigación y de análisis predominante fue la semiótica discursiva de la escuela de París, fundada por Greimas. De forma complementaria, establecimos diálogos permanentes con propuestas teóricas y metodológicas provenientes de la hermenéutica, la sociología, la antropología, el psicoanálisis y la psicología, postura interdisciplinaria útil para enfrentar la complejidad de la lectura de los discursos y del objeto de estudio. Esta decisión metodológica implicó considerar lo siguiente:

1. Desde su formación en las décadas de 1950 y 1960 a la actualidad, la semiótica francesa y europea se ha transformado de forma significativa. Se pasó de una perspectiva formalista y estructuralista a una semiótica narrativa y, en la actualidad, discursiva y de la cultura. Al respecto, Fontanille expresa:

De forma progresiva, la semiótica se ha convertido en una semiótica del discurso, en consecuencia, ha asumido aquello para lo cual fue pensada: elaborar una teoría de los conjuntos significantes y no una teoría del signo [...]. La semiótica se ha convertido en una semiótica del discurso que ubica todo en el acto de enunciación, en las operaciones enunciativas, y no solo en la representación del "personal" de la enunciación (narradores, observadores, etc.) en el texto. De esa manera, puede tratar el texto literario no solo como un enunciado con formas específicas, sino también como una enunciación particular, una "palabra literaria", como afirmaría Jacques Geninasca. ${ }^{17}$

2, A partir del punto de vista anterior, las significaciones de novelas como Scorpio City, Relato de un asesino y Satanás, o de las declaraciones dadas por los criminales, no pertenecen a los textos en sí mismos, sino a toda una situación enunciativa en la que participan las historias enunciadas, los lectores y los entornos sociales y culturales en los que los discursos fueron creados y son recreados.

3. El análisis semiótico se orientó por tres principios de todo discurso con vocación científica: adecuación, exhaustividad y simplicidad, teniendo claro que

la semiótica no pretende, en absoluto, extraer el sentido de un texto; esta se propone, a lo sumo, efectuar la descripción de la significación primaria (o del sentido lingüístico medio, en el caso del lenguaje verbal), dejando a las otras ciencias humanas, mejor provistas, el cuidado de avanzar en la comprensión y la interpretación de los discursos, de obtener las significaciones secundarias. ${ }^{18}$

4. Debido a que "los textos se presentan al lector como bloques impenetrables de significación", 19 realizamos el análisis a través de un recorrido interpretativo-generativo que focalizó, fragmentó y relacionó los niveles de pertinencia del análisis más concretos con los más abstractos para corroborar las hipótesis de lectura. Es decir, las figuras actoriales, espaciales y temporales, así como las configuraciones narrativas, temáticas, actanciales y fundamentales de los discursos, se describieron, compararon y contrastaron para inferir prácticas y formas de vida de un entorno histórico, social

17 Jacques Fontanille, Sémiotique et littérature: Essais de méthode (París: Presses universitaires de France, 1999), 2. La traducción es mía.

18 Joseph Courtés, Análisis semiótico del discurso: Del enunciado a la enunciación (Madrid: Gredos, 1997), 98-299.

19 Graciela Latella, Metodología y teoría semiótica (Buenos Aires: Hachette, 1986), 67. 
y cultural como Colombia. En otras palabras, el ejercicio interpretativo no pretendió explicitar las estructuras narrativas en sí mismas y de forma aislada, sino que reconstruyó las isotopías enunciadas sobre el objeto semiótico de estudio, con la descripción y la relación dinámica entre los niveles de pertinencia mencionados. Lo anterior implicó establecer relaciones intertextuales de forma constante, que siempre mantuvieron como punto de origen y referencia la Colombia enunciada en los discursos. De esta manera, el trabajo analítico y la metodología semiótica podrían dar prueba de una ambición más alta, que, lejos de eliminar el contexto sociohistórico, podrían pensar su relación con los textos como una relación de intersemioticidad. ${ }^{20}$

5. La investigación y el análisis se ubicó en el plano de la enunciación-enunciada y se centró, en especial, en las identidades discursivas de los sujetos enunciados o actores y narradores de las historias.

\section{Resultados}

\section{Construcción discursiva de la identidad}

Como resultado de la investigación y del análisis semiótico, se da cuenta de la configuración de cada uno de los componentes del esquema narrativo expuesto en el cuadro 1, que ubica en la parte superior la construcción discursiva de la identidad. Este es el punto de partida, porque, para comprender la negación de la identidad y su relación con la violencia y la criminalidad, es preciso conocer el proceso de construcción de lo negado. En este caso, la identidad discursiva de los tres criminales protagónicos de las novelas: un sujeto que se hace denominar "el Apóstol” (Scorpio City), otro identificado como "el Loco Tafur" (Relato de un asesino) y "Campo Elías" (Satanás). Las identidades de estos personajes coinciden con las enunciadas por criminales reconocidos en Colombia y el exterior como Pedro Alonso López, alias "el monstruo de los Andes"; Luis Alfredo Garavito Cubillos; Jhon Jairo Velásquez Vásquez, alias "Popeye", entre otros.

Se resalta que gran parte del recorrido analítico se organiza en atención a nuestra concepción sobre lo que es y acontece en la enunciación, escenario de la construcción discursiva de la identidad. Al respecto, Serrano Orejuela afirma:

Todo texto, oral o escrito, producido en una práctica discursiva (la cual moviliza modos y tipos discursivos y géneros textuales), se estructura en tres planos interrelacionados: el de la enunciación (en el cual se inscriben el enunciador y el enunciatario), el del enunciado (mediante el cual el enunciador se dirige al enunciatario) y el del referente (al cual refiere el enunciador mediante el enunciado). Enunciador, enunciatario y referente son roles discursivos inscritos en el texto, diferentes por tanto del escritor o hablante, el lector u oyente y el mundo en que estos viven. ${ }^{21}$

Desde esta postura, la puesta en acto del discurso o enunciación genera una red compleja entre los sujetos actuantes en una situación determinada, relaciones que modalizan y determinan la construcción

20 François Rastier, Semántica interpretativa (México: Siglo XXI, 2005), 102.

21 Eduardo Serrano Orejuela, “Narración, argumentación y construcción de identidad”, en Didáctica del discurso, ed. por María Cristina Martínez (Cali: Universidad del Valle, 2005), 98. 
identitaria de cada uno de los sujetos involucrados en el evento discursivo. A través de sus enunciados, el enunciador se identifica y construye la identidad discursiva de su enunciatario; de igual manera, cuando el enunciador refiere a alguien, propone una identidad para el sujeto o sujetos referidos que puede ser él mismo o su grupo social usando la primera persona, el enunciatario convocando la segunda persona o un sujeto diferente de los anteriores representado con la tercera persona. Desde Serrano, este planteamiento se puede graficar como un esquema en forma de $\mathrm{Y}$ :

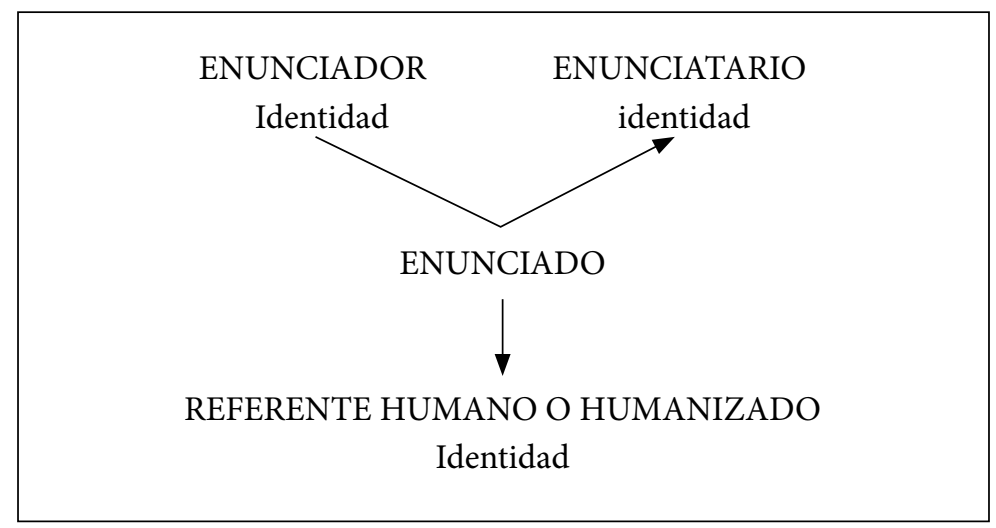

Cuadro 2. Planos enunciativos de la identidad discursiva ${ }^{22}$

El escenario enunciativo instaura así tres lugares interconectados de construcción discursiva de la identidad: el espacio del enunciador, el del enunciatario y el del referente humano o humanizado. A partir de este punto de vista, se analiza la autorreferencia o representación para sí mismos y para los otros de las dimensiones y constituyentes identitarios de los sujetos criminales.

Los criminales estudiados enuncian sus cuerpos enfermos, débiles y maltratados, por ejemplo, "el Loco Tafur" recuerda su niñez y observa su cuerpo de la siguiente forma:

Mi caso, para ser sincero, era bastante patético. A los seis años de edad había sufrido una apendicitis que degeneró en una peritonitis. [...] permanecí siete meses en la clínica, y, luego de una reunión general, los médicos de la institución decidieron declararme como "paciente desahuciado", es decir, como un enfermo cuya muerte era cuestión de horas. ${ }^{23}$

De forma similar, Daniel Camargo Barbosa ${ }^{24}$ manifestó que su madrastra:

22 Serrano, "Narración, argumentación, identidad", 98.

23 Mario Mendoza, Relato de un asesino (Bogotá: Planeta, 2001), 10, 12.

24 Homicida colombiano alias de "el Sádico de El Charquito". 
Para castigarme, me quitaba los pantalones y me ponía unas enaguas de mujer; yo me escondía en una pieza, pero ella, no contenta, llevaba a mis compañeros del colegio hasta donde me escondía y les decía "miren". Me ponía de esta manera en una situación muy dolorosa. ${ }^{25}$

Asimismo, Luis Alfredo Garavito Cubillos ${ }^{26}$ confesó: “Tenía 12 años y, un día de tantos, el mejor amigo de mi padre, aprovechando ciertas circunstancias, me torturó y me violó”. ${ }^{27}$ En estos enunciados, los criminales no solo refieren sus cuerpos como fuentes de debilidad, enfermedad, maltrato y burla, sino que también dan cuenta de la evaluación negativa que hacen los otros de la dimensión corporal de los infantes. En este caso, "los médicos", la "madrastra" y el "amigo" del padre relacionan los cuerpos de los niños con la muerte, con objetos de placer y violencia.

Por otra parte, el carácter o las disposiciones duraderas de las identidades discursivas de los criminales se caracterizan por prácticas y roles temáticos disfóricos como la agresividad, el resentimiento, el individualismo, la soledad, entre otros estados y formas de actuar. Por ejemplo, Campo Elías se enuncia de la siguiente manera,

Octubre 12: El inicio de un diario es un ejercicio cotidiano de introspección y certifica la inmensa soledad de quien lo escribe. Y sí, eso es lo que soy, un solitario sin remedio, porque, por más que intento acercarme a los otros y entablar con ellos alguna relación duradera, no lo logro. ${ }^{28}$

El historiador Germán Arciniegas recordaba al asesino "el Hombre Fiera”, capturado durante la primera década del siglo XX en el panóptico municipal de Tunja: "Los delincuentes que llegaban allá formaban sus amistades, se entendían en las horas de salida a los patios, recibían visitas de los familiares. Solo él permanecía solo". ${ }^{29}$ De esta forma, Campo Elías y "el Hombre Fiera" se configuran como sujetos disjuntos de los demás actores del entorno social. Ahora bien, aunque Campo Elías desea las relaciones sociales, las costumbres e interacciones polémicas que constituyen su carácter siempre lo conducen a la soledad.

La dimensión cultural de las identidades discursivas de los criminales actualiza e invierte el sentido de valores correspondientes a sistemas axiológicos estéticos, éticos, semióticos y tecnológicos. En otras palabras, los valores negativos de la cultura a la que pertenecen los criminales se tornan positivos para ellos o valores positivos de la cultura devienen negativos. Para ilustrar lo anterior, la percepción estética de "el Loco Tafur" impulsa su atracción por lo grotesco y culturalmente repulsivo: "No visité el cementerio donde estaban enterrados mis padres ni una sola vez. Cambié la tumba por el burdel y el ataúd por el orgasmo". ${ }^{30}$ La ética de Andrés Leonardo Achipiz ${ }^{31}$ vierte en el "sicariato" o asesinato a sueldo los valores

25 Esteban Cruz Niño, Los monstruos en Colombia sí existen (Bogotá: Random House, 2013), 82.

26 Violador y homicida nacido en Génova, Quindío, Colombia.

27 Cruz, Los monstruos Colombia, 115.

28 Mario Mendoza, Satanás (Bogotá: Planeta, 2002), 121.

29 Cruz, Los monstruos Colombia, 228.

30 Mario Mendoza, Relato de un asesino (Bogotá: Planeta, 2001), 121.

31 Confesó haber asesinado a más de 30 personas en Bogotá. 
positivos del trabajo y la remuneración económica: "lo empecé a hacer como por trabajo, como el día a día, como que hoy me levanto y bueno, te entró la llamada y qué hay qué hacer". ${ }^{2}$

La inversión de los valores que componen la axiología de los criminales impulsa y direcciona a la dimensión social de sus identidades discursivas a establecer y promover relaciones cooperativas con sujetos similares; por esa razón, para "el Loco Tafur" la zona de tolerancia se convirtió en su segundo hogar. Compartiendo con habitantes de calle, prostitutas o hechiceros, a los cuales reconoce como amigos, se siente "sin nervios, tranquilo, en calma, gozando a plenitud de la increíble sensación de ser yo mismo" ${ }^{33}$ Esto es útil para explicar el trasfondo axiológico y afectivo de la conformación de grupos delincuenciales, el paso de los criminales de un colectivo delincuencial a otro, la exaltación e identificación con los representantes de aquellos valores negativos transformados en positivos, hasta el punto de sacralizarlos. Así lo expresaba Jhon Jairo Velásquez Vásquez, alias "Popeye": "Yo amaba a Pablo Escobar, mi mayor satisfacción era ver a Pablo Escobar contento. [...] Era totalmente feliz y andar con Pablo Escobar era una cosa de locos, era mi dios". ${ }^{34}$

Debido al carácter estratégico de la dimensión de las representaciones sociales en las identidades discursivas, los sujetos criminales llegan a ocultar estados afectivos como el miedo o la compasión con tal de cumplir los valores de grupo y la imagen que deben proyectar como sujetos de poder. Por ejemplo, "el Loco Tafur" se construye y observa a sí mismo como sujeto temeroso y víctima: "Sentí un miedo tremendo de que los demás fueran testigos de la extraña transformación de la que era víctima". ${ }^{35}$ Sin embargo, a través de su hacer, para los otros enuncia una imagen distinta como sujeto valiente y victimario: "Fue tanto el miedo que decidí actuar para esconder lo que en realidad me estaba ocurriendo: me le fui encima al Simio y le metí un cabezazo en plena nariz" ${ }^{36}$ En postura similar, Luis Alfredo Garavito Cubillos proyecta y encubre a la vez la imagen negativa de sí mismo a través de su admiración por personajes como Adolf Hitler: "Admiraba mucho a Hitler; quería llegar a ser como él, conseguir poder para hacerme respetar. Siempre anhelé ser importante, estar en la televisión. En la prensa, que todo el mundo hablara de mí". ${ }^{37}$

\section{Encuentro con un yo-sí mismo y otros que se niegan}

La cita final del apartado anterior es útil para dar cuenta de un querer no ser, es decir, un deseo orientado a negar el ser o la construcción identitaria que el sujeto ha realizado para sí mismo y para los demás. El discurso de Garavito Cubillos da cuenta de la negación de un sí mismo falto de poder, respeto y reconocimiento. Un caso extremo de negación de la identidad, por ende, de disforia y valoración negativa de sí mismo, acontece en Satanás cuando Campo Elías enuncia: "Cuando estoy frente al espejo solo veo un pedazo de mierda". ${ }^{38}$

32 Noticias Caracol Televisión, “Joven de 19 años confiesa que mató a más de 30 personas”, acceso el 31 de octubre de 2021. https://www.youtube.com/watch?v=PW_a5hv_XP4.

33 Mendoza, Relato de un asesino, 134.

34 Frank Periodista, "Entrevista a Popeye", acceso el 31 de octubre de 2021, https://www.youtube.com/ watch?v=5xqWULtL31Q.

35 Mendoza, Relato de un asesino, 37.

36 Mendoza, Relato de un asesino, 37.

37 Cruz, Los monstruos Colombia, 121.

38 Mendoza, Satanás, 145. 
Las dimensiones y los constituyentes de las identidades discursivas de los criminales y de los sujetos que ellos consideran igual o más despreciables son objeto de relaciones tensas y polémicas. De esta manera, el cuerpo, el carácter, las relaciones sociales, la cultura, la cognición, los valores y los estados afectivos son rechazados, así es como Campo Elías desprecia su origen y el entorno sociocultural colombiano: "Pero qué se puede esperar de un país donde todo el mundo tiene mentalidad de limosnero [...] Colombia no es un país, sino una orden mendicante". ${ }^{39}$

Así pues, la negación de la identidad por parte de los criminales produce un despertar afectivo disfórico que se incrementa progresivamente con efectos nefastos, analizados más adelante. Por ahora, es trascendente develar el surgimiento de disforias como el temor por sí mismos y sus actos, es el caso de Javier Velasco Valenzuela, ${ }^{40}$ quien declaró respecto del asesinato de Rosa Elvira Cely: "Yo creo que fue un acto de brutalidad de parte mía [...] terriblemente asustado". ${ }^{41}$ Asimismo, en el diario de Daniel Camargo Barbosa, se puede leer: "Repentinamente me invadió un terror que de ninguna manera podía controlar. Vinieron a mi mente los seis años de reclusión, la monotonía propia de las cárceles, la horrible sensación que se ha perdido la libertad; recordé que mi fotografía estaba en el álbum dedicado a los violadores". ${ }^{42}$

La memoria y sanción negativa de su fotografía evidencia la postura de Camargo Barbosa frente a un yo temido y rechazado, así como "el Loco Tafur" se observa en Relato de un asesino: "Una cosa es el dolor físico, el de la materia, y otra muy distinta es el horror de verse en el espejo y reconocer allá, al otro lado del cristal, la sonrisa perversa de nuestro peor enemigo". ${ }^{43}$ Estas negaciones de las identidades tienen un efecto de sentido, a manera de espejo, en el cual los sujetos criminales focalizan en los otros todo aquello que niegan en sí mismos. Los otros son configurados como un reflejo del sí mismo aborrecido, que los convierte en víctimas potenciales o enemigos efectivos. La negación de sí mismos, transformada en desprecio por los otros, puede ser comprendida a partir de las posturas de Freud sobre los instintos de vida y de muerte:

Además del Eros había un instinto de muerte; los fenómenos vitales podrían ser explicados por la interacción y el antagonismo de ambos [...] el propio instinto de muerte sería puesto al servicio de Eros, pues el ser vivo destruiría algo exterior, animado o inanimado. En lugar de destruirse a sí mismo. Por el contrario, al cesar esta agresión contra el exterior tendría que aumentar por fuerza la autodestrucción, proceso que de todos modos actúa constantemente. ${ }^{44}$

La relación que se puede establecer entre nuestra visión semiótica de la identidad discursiva, su negación y lo postulado por Freud es que en los criminales estudiados existe una dimensión corporal y un carácter en tensión disfórica permanente debida a su origen y dimensiones sociales y culturales. Ese conflicto se fundamenta, con frecuencia, en un querer no ser lo que se es. Malestar que, animado por la autorreferencia y los discursos ajenos negativos, empieza a proyectarse al exterior a través de contratos

39 Mendoza, Satanás, 123, 124.

40 Asesino también de Dismila Ochoa Ibáñez en Bogotá.

41 Cruz, Los monstruos Colombia, 247.

42 Cruz, Los monstruos Colombia, 93.

43 Mendoza, Relato de un asesino, 32.

44 Sigmund Freud, El malestar en la cultura (Madrid: Alianza, 2015), 119. 
sociales polémicos, confrontaciones y destrucción de los otros, tal como lo manifiesta John Jairo Moreno Torres, ${ }^{45}$ alias “Johnny el Leproso", al escupir y patear el cadáver de Fernando González Palma, persona a la que acababa de asesinar: "Esto es para que no se olviden de Johnny el Leproso". ${ }^{46}$ Un desprecio similar hace presente el discurso de Campo Elías: "Observo desde mi lejanía el comportamiento de aquellos que me rodean y no me identifico con ellos. Los veo como bichos de otra especie, como animales raros cuya conducta no deja de sorprenderme". ${ }^{47}$

\section{Despertar, disposición e inclinación pasional disfóricos}

La negación de las identidades discursivas de los criminales, que conduce a contratos polémicos permanentes con su sí mismo y con la sociedad, los convierte en sujetos solitarios, excluidos y les despierta un cúmulo de estados pasionales, en especial disfóricos, intensos y extensos, que constituyen su afectividad, cuerpo y carácter. Esos estados impulsan la transgresión o transformación de los valores aceptables de la cultura.

A partir de la semiótica, las pasiones se entienden como estados del alma que modalizan el ser-estar de los sujetos discursivos. Tales estados pueden ser disfóricos (negativos) o eufóricos (positivos), y se despiertan en el contacto de los sujetos con el mundo. "El despertar afectivo es la etapa durante la cual el actante es 'sacudido': su sensibilidad es despertada, una presencia afecta su cuerpo" ${ }^{48}$ Esa presencia puede estar representada por el sí mismo, los otros u objetos del mundo natural. Lo anterior explica el despertar y la permanencia continua de las pasiones como constituyentes de las identidades discursivas.

Los criminales estudiados se caracterizan por estar modalizados de forma recurrente por pasiones negativas. Esto permite afirmar que en ellos existe una disposición e inclinación pasional disfórica impregnada en sus dimensiones corporales y del carácter, que contribuye a su individualización e identificación actorial como personajes disfóricos. ${ }^{49}$ Cabe anotar que la disposición pasional corresponde a la "etapa en el curso de la cual se precisa el género de la pasión", ${ }^{50}$ es decir, es un momento de la configuración pasional en el que los sujetos no solo sienten, sino que también significan e identifican su estado como eufórico o disfórico.

De la diversidad de estados disfóricos enunciados por los criminales, se destacan el miedo, el rencor, el resentimiento, el odio y la venganza. En Scorpio City y Satanás, “el Apóstol” y Campo Elías sienten, se comportan y enuncian como sujetos resentidos y vengativos. El primero expresa: "Hoy, por fin, unos instantes antes de morir, he de vengarme". ${ }^{51}$ El segundo piensa que su vida es "cruel, inhumana, llena de odio y resentimiento". ${ }^{52}$ Estas pasiones coinciden con las enunciadas por Camargo Barbosa, quien

45 Asesinado en la cárcel Modelo de Bogotá en 1998.

46 Cruz, Los monstruos Colombia, 237.

47 Mendoza, Satanás, 121.

48 Jacques Fontanille, Semiótica del discurso (Lima: Fondo de Cultura Económica, 2001), 108.

49 Francesco Marsciani, “Pasión”, en Diccionario razonado de la teoría del lenguaje (Madrid: Gredos, 1991 ), 187.

50 Fontanille, Semiótica del discurso, 108.

51 Mario Mendoza, Scorpio City (Bogotá: Planeta, 1998), 35.

52 Mendoza, Satanás, 146. 
relató lo siguiente sobre sus sentimientos ante su cónyuge: “Tuve el deseo de hacerle daño, de vengarme, destruirla" ${ }^{53}$ Por su parte, Andrés Leonardo Achipiz refirió la rabia contenida o el rencor experimentado: "el maltrato lo hace sentir a uno como oprimido, con una rabia oprimida" 54 .

El constituyente pasional en la identidad discursiva es tensivo, es decir que su valor positivo o negativo es irregular, oscilante, más o menos intenso o extenso, por ello, el desagrado puede devenir en ira, el temor en pánico o la frustración en rencor. Así, las pasiones disfóricas de los criminales se caracterizan por una alta intensidad que los hace "estallar" fácilmente en su afectividad y los pone al borde del sin sentido, como relata "el Loco Tafur": "Una nube de ira me impide ver lo que sucede a mi alrededor. El corazón me late deprisa y siento sus pulsaciones aceleradas en las sienes, como si tuviera bombas de tiempo en el cerebro".55 Lo mismo acontece con pasiones eufóricas fundadas en valores negativos como el sufrimiento. Así, ante la pregunta, “¿Qué sentías con las expresiones de dolor de la gente?”, el exintegrante de una banda criminal, alias "Robinson", respondió: "A veces le daba como más ánimo de seguir haciéndolo, se le subía la moral”"56 Este testimonio explicita cómo la euforia intensa del criminal transformaba el sufrimiento ajeno en valor positivo, y lo deja suficientemente modalizado para el sin sentido y desbordarse en actos de violencia.

\section{Sinsentido y sin sentido: crisis y desaparición del lenguaje y de la identidad discursiva}

Existen tres conceptos clave para comprender la relación entre la ruptura del principio de regulación del discurso y la negación de la identidad discursiva de los criminales: emergencia de sentido, sinsentido y sin sentido, insinuados por A. J. Greimas y Eric Landowski. ${ }^{57}$ Este triduo también explica la función vital del principio de regulación del discurso ${ }^{58}$ en la existencia semiótica y la identidad discursiva de los sujetos, porque con y a través del lenguaje se teje el sentido del yo y de la vida, se armonizan y estabilizan las dimensiones y constituyentes de las identidades discursivas.

Al respecto, es preciso explicar que los seres humanos no solo vivimos, también tenemos la necesidad vital de dar sentido a esa vida, es decir que a través del lenguaje debemos crear una existencia semiótica de la vida, lo que es una constante "emergencia de sentido", 59 pues todo sujeto establece relaciones con él mismo, con los demás y con el mundo que lo rodea para otorgarles un valor, enunciarse y enunciar a los demás el sentido de sí mismo, de los otros y del mundo en general. Por ello, el discurso es un regulador

53 Cruz, Los monstruos Colombia, 85.

54 Noticias Caracol Televisión, “Joven de 19 años confiesa que mató a más de 30 personas”, acceso el 31 de octubre de 2021. https://www.youtube.com/watch?v=PW_a5hv_XP4. En el análisis de la amargura, el resentimiento y el rencor, Algirdas Greimas destaca la manifestación animosa y hostil de estas pasiones "que acompañan este descontento duradero (que definimos como un 'recuerdo' presente) tiene el mismo aire de familia que la 'agresividad' que entra en la definición de la cólera”. Del sentido II (Madrid: Gredos, 1989), 268.

55 Mendoza, Relato de un asesino, 184.

56 Contravía, "Confesión de un exparamilitar", acceso el 31 de octubre de 2021, https://www.youtube.com/ watch?v=TOFsMqEhDeQ.

57 La lengua española provee términos que no son idénticos "sinsentido" y "sin sentido".

58 Principios del discurso propuestos por Patrick Charaudeau, "Las emociones como efectos de discurso", acceso el 31 de octubre de 2021, http://www.patrick-charaudeau.com/Las-emociones-como-efectos-de.html.

59 Para profundizar en el concepto, véase Eric Landowski, “Tres regímenes de sentido y de interacción”, Tópicos del Seminario, n. 14 (2005): 165. 
esencial en el devenir de la existencia semiótica de los sujetos, existencia caracterizada por relajaciones y tensiones, estabilidades y crisis. ${ }^{60}$

De ahí que el sinsentido sea una crisis del sentido de la vida o de la relación que el sujeto establece consigo mismo o con otros sujetos u objetos, implica el deterioro de los valores positivos vertidos en estos, para convertirlos en negativos. En esa crisis, la vida, el sí mismo, los demás o el mundo se tornan absurdos, incoherentes, desagradables e insoportables. En consecuencia, el sinsentido no deja de ser un sentido, también es un sentido degradado de las identidades discursivas o de la vida, como lo enuncia Campo Elías en Satanás:

Mi vida no tiene ninguna esperanza. Ya es tarde para hacerme ilusiones. Detesto la existencia que llevo, no hay nada alrededor mío que me entusiasme, que me dé confianza en el futuro, que me obligue a luchar para salir de los infiernos. [...] Una vida vacía y sin sentido, cruel, inhumana, llena de odio y resentimiento. ${ }^{61}$

A pesar del uso de la expresión "sin sentido", es evidente que se trata de un efecto de sinsentido. Campo Elías, como sujeto observador de sí mismo, percibe y evalúa su existencia, y genera la función y presencia del objeto vida. En otras palabras, aunque la vida parece vacía de sentido, Campo Elías la ubica como un objeto frente a sí, la sanciona de forma negativa y le otorga existencia para sí mismo, pese a la degradación de su valor y repulsión. De forma similar, las declaraciones de alias "Robinson" son útiles para ilustrar el sinsentido en que cae la vida de los otros: "a veces me levanto como con rabia contra la gente con ganas de seguir haciéndolo [...] ganas de seguir matando". ${ }^{62}$

En estados de sinsentido como el de Campo Elías o "Robinson", el discurso regula al sujeto para resignificar el mundo, encontrar salidas a la crisis, estabilizar y recuperar el valor de la existencia semiótica; pero, si esto no acontece, emerge la posibilidad del caos semántico o sin sentido que, según Van Alphen, es una "incapacidad semiótica”, es decir, una pérdida de la mediación del lenguaje y una ruptura total de la relación sujeto-sí mismo, otros, mundo. ${ }^{63}$ Esta fractura del discurso, de la existencia semiótica y de la identidad discursiva, tiene efectos desastrosos en el cuerpo-agente, ${ }^{64}$ consecuencias que Greimas y Fontanille analizan de la siguiente manera:

60 El discurso se asume en una perspectiva amplia, como construcción, acto y manifestación del lenguaje a través de la lengua, los gestos, los colores, los sabores, entre otros sistemas semióticos.

61 Mendoza, Satanás, 145, 146.

62 Contravía, "Confesión de un Exparamilitar", acceso el 31 de octubre de 2021, https://www.youtube.com/ watch?v=TOFsMqEhDeQ.

63 Ernest van Alphen, “Experiencia, memoria y trauma: Síntomas de discursividad”, en Trauma, cultura e historia: Reflexiones interdisciplinarias para el nuevo milenio, ed. por Francisco Ortega (Bogotá: Universidad Nacional de Colombia, 2011), 204.

64 A partir de las características lingüísticas del griego clásico, Van Alphen y White consideran el concepto de voz intermedia que "sitúa al agente dentro de la acción. El agente toma parte en la acción, o en el evento, sin ser ni sujeto ni objeto de esta. Al agente lo afecta la acción sin ser directamente objeto o sujeto de la misma". Alphen, "Experiencia, memoria y trauma", 204. Desde esa noción, es posible afirmar que los criminales analizados han sido entonces agentes participantes en eventos violentos y criminales, pero, en el instante mismo de las agresiones físicas y de los asesinatos, con frecuencia no experimentan esos hechos como tal porque no son ni sujetos, ni objetos de estos, lo que explica la sevicia de algunos crímenes. Al respecto, es imprescindible considerar que una situación puede no ser experimentada cuando la ausencia del lenguaje en el agente no le permite configurar la función sujeto-objeto, debido a que no hay marcos narrativos convencionales desde el punto de vista de los cuales la realidad pueda ser trabajada. Los eventos parecen ocurrir en una especie de vacío. 
Mientras que, en la percepción, el cuerpo humano tenía el papel de instancia de mediación -es decir, era un lugar de transacción entre lo extero y lo interoceptivo e instauraba un espacio semiótico tensivo pero homogéneo-, ahora es la carne viva, la propioceptividad "salvaje" la que se manifiesta y reclama sus derechos en tanto "sentir" global. Ya no es más el mundo natural el que adviene al sujeto, sino el sujeto quien se proclama dueño y señor del mundo, su significado, y lo reorganiza figurativamente a su manera. ${ }^{65}$

Esto quiere decir que, a pesar de su presencia física y transcurrir en el mundo, los órganos sensoriales de los criminales están cerrados a la percepción y al lenguaje que procesa las experiencias sensoriales, actividades fundamentales para producir sentido. En esos instantes de sin sentido, la "carne viva y propioceptividad salvaje" de los cuerpos de los criminales limita sus competencias de forma significativa o totalmente, son afectadas por una "hipoestesia" o "trastorno de la percepción que consiste en una distorsión sensorial a causa de una disminución de la intensidad de las sensaciones, de tal forma que los estímulos se perciben de una forma anormalmente atenuada". ${ }^{6}$

Es preciso considerar que ese estado de desorientación suele ser precedido por un exceso de homogeneidad o situación rutinaria desmedida, o de heterogeneidad o ausencia de un hilo conductor de la existencia semiótica y de las identidades discursivas de los criminales.

\section{Conclusiones: violencia y muerte de los otros y del sí mismo como otro}

$\mathrm{Al}$ quebrantarse la función sujeto-sí mismo/otros/mundo (objetos), la existencia semiótica se virtualiza y el agente queda fuera de sí. ${ }^{67}$ En un abismo respecto del sentido común organizador del mundo que lo rodea, sus dimensiones y constituyentes identitarios se dislocan con resultados imprevisibles, por ejemplo, su cuerpo se altera, deja de percibir y deviene un organismo desorientado, atrapado en el vacío.$^{68}$ Este estado de aislamiento explica una violencia criminal que, en gran parte de los casos, resulta inexplicable para el sujeto que vuelve en sí de esa fractura discursiva inaceptable para el entorno cultural.

65 Algirdas Greimas y Jacques Fontanille, Semiótica de las pasiones (Madrid: Siglo XXI, 1994), 18.

66 Clínica Universidad de Navarra, "Hipoestesia”, acceso el 31 de octubre de 2021, http://www.cun.es/diccionariomedico/terminos/hipoestesia.

67 Fenómeno y efecto conocido en psicología como despersonalización, el cual consiste en “la sensación persistente o recurrente de estar separado de sus procesos mentales o de su cuerpo' (DSM IV) el mundo parece extraño a menudo también, y se llama desrealización. Los objetos físicos pueden parecer distorsionados y la gente puede parecer mecánica. [...] La mitad de los adultos pueden haber experimentado un breve episodio de despersonalización o de desrealización en el curso de la vida, pero es más común en personas que han sufrido abuso, la pérdida de un ser querido, o haber visto la guerra. Es también común bajo la influencia de alucinógenos como el LSD”. George Boeree, "Psicología general: Trastornos disociativos", acceso el 31 de octubre de 2021, http://www.psicologia-online.com/ ebooks/general/trastornos-disociativos.html.

68 Sobre estas reacciones, en Scorpio City se cita el artículo psiquiátrico de Joseph Satten incluido por Truman Capote en A sangre fría: "En los cuatro casos existen pruebas de estados alterados de conciencia en el pasado y con frecuencia relacionados con los ataques de violencia. Dos de los hombres presentan estados parecidos a un trance disociativo en los que se verifica un comportamiento incoherente y violento, mientras los otros dos presentan episodios amnésicos menos graves y quizá menos completos". Mendoza, Scorpio City, 60. 
Los cuerpos de "el Loco Tafur" y Javier Velasco Valenzuela encarnan esos vacíos de sentido en variadas circunstancias, en especial, las caracterizadas por el estrés, la ira y la violencia. En la declaración sobre el asesinato de Dismila Ochoa Ibáñez, Velasco declaró: "Yo le introduje el machete y [...] hasta ahí me acuerdo [...] tal vez enceguecido". 69 "El loco Tafur" recuerda su sensación de pánico ante la posibilidad de la nada:

Sentí de nuevo el ataque, la niebla que ingresaba en mi cerebro y oscurecía el mundo a mi alrededor. Sentí un miedo tremendo [...] Yo estaba combatiendo en realidad contra mí mismo, contra el misterioso efluvio mental que había empezado a tomarse mi cerebro desde esa misma tarde, y que buscaba expulsarme de mi cuerpo y mandarme afuera, al mundo de la nada. ${ }^{70}$

Del pasaje anterior se destacan cuatro figuras que representan el sin sentido: niebla-oscuridad/afueranada, las cuales presuponen la ausencia de sus contrarios, claridad-lucidez/adentro-existencia. La ausencia de esos valores inquieta a "el Loco Tafur" porque lo deja por fuera de un mundo que le exige significar y ser significado.

En las situaciones descritas por Velasco y "el Loco Tafur", se presenta una disociación cuerpo-actante sujeto en que este último se ausenta por completo. Solo hay reacciones caóticas y violentas de un cuerpo aislado de la existencia semiótica, por tanto, ni siquiera es posible hablar de actuación del sujeto. ${ }^{71}$ Como reconstrucción semiótica y discursiva, la memoria también se afecta en esos instantes de vacío de sentido, por ello, Velasco y "el loco Tafur" describen episodios de los asesinatos, pero no logran recordar otros.

$\mathrm{Al}$ regresar del sin sentido y ante la complejidad de explicar su actuar desajustado, resulta común que los criminales ofrezcan razones míticas, espirituales, ideológicas o altruistas para justificar su violencia. Cristopher Chávez Cuellar, ${ }^{72}$ alias "el Desalmado", apeló a lo sobrenatural para dar cuenta de los homicidios perpetrados, "pido perdón a las víctimas por ese hecho desde luego que me poseyó una fuerza sobrenatural que me llevó a hacerlo y sí lo hice". ${ }^{73}$ Pedro Alonso López expuso motivos ideológicos y altruistas después de su captura por múltiples asesinatos de niñas:

Por ahora, ayudar a encontrar más de mis muñequitas; después me voy a seguir mi obra a los Estados Unidos, porque allá hay muchas niñas que sufren y yo lo que estoy es cumpliendo con un deber revolucionario [...] Estaré encantado de volver a matar. Esa es mi misión. ${ }^{74}$

69 Cruz, Los monstruos Colombia, 247.

70 Mendoza, Relato de un asesino, 37.

71 La actuación de un sujeto presupone la existencia de competencias que permiten la actualización de los valores necesarios para configurar y adaptar su identidad discursiva a la situación. Este proceso implica que el sujeto de hacer reconozca las posiciones e identidades discursivas de los otros interactuantes. Sin embargo, durante el sin sentido el poder del cuerpo se aísla de la orientación de las competencias y la axiología, el sujeto queda incapacitado para adaptarse y actuar de acuerdo con las circunstancias y presenta reacciones inesperadas y caóticas.

72 Asesino de cuatro niños y hermanos en Florencia, Caquetá.

73 Noticias Caracol, "Me poseyó una fuerza sobre natural”: alias el Desalmado confiesa crimen, acceso el 31 de octubre de 2021, https://noticias.caracoltv.com/colombia/me-poseyo-una-fuerza-sobrenatural-alias-el-desalmado-confiesacrimen.

74 Cruz Niño, Los monstruos Colombia, 49, 70. 
De esta manera, el hiperrealismo literario de Mario Mendoza, las narrativas académicas y las narrativas periodísticas dejan percibir un esquema narrativo subyacente a la actuación violenta y criminal de unos actores determinados. Es innegable que el universo de intenciones y motivos que impulsa el actual criminal es diverso, a pesar de ello, la identidad discursiva del criminal está involucrada, porque, como se planteó, el ser y el hacer de los sujetos depende de los simulacros discursivos de sí, de los otros y del mundo en general.

En los criminales analizados, se observa una pérdida sucesiva de sujetos y objetos de valor positivo, un proceso social e individual de degradación de sus identidades discursivas que los conduce a negarlas o a un querer no ser. Lo anterior los modaliza para vivir en una tensión disfórica intensa y permanente. En algunos casos insoportable, que se manifiesta en la agresión o asesinato del otro como forma de autodestrucción. Debido a la negación de la identidad llegan a no temer a la muerte, todo lo contrario, la desean y la buscan, como se puede percibir en el discurso de Jhon Jairo Velásquez Vásquez, alias "Popeye": "Yo andaba en las calles de Medellín con un fusil Galil 762, una pistola 10 milímetros en la pretina de mi pantalón y en mi carro cargaba 4 o 5 granadas, estaba listo para morir y peliar duro". 75

Como impulso de vida y debido al principio de regulación del discurso, los criminales buscan restaurar su identidad, al menos para sí mismos, con una violencia compensadora. ${ }^{76}$ En consecuencia, la maldad y la destrucción del otro los reconfigura y hace sentir poderosos y trascendentes. La violencia y el crimen se transforman en una forma de vida basada en una inversión de los valores negativos en positivos. Desde la semiótica de la cultura, la costumbre está integrada en una forma de vida, es decir, en una manera de ser y hacer. Los criminales analizados incorporaron la violencia a sus formas de vida. Son violentos para identificarse, hacer existir y hacer valer sus identidades. Esta reivindicación de su sí mismo solo tiene una posibilidad de expresión: el actuar violento. En el ser y actuar violento, los criminales citados encuentran admiración de otros personajes similares e intimidación y abuso de poder sobre sus víctimas, lo cual presupone un deseo de reconocimiento y un sentido de identidad basado en valores negativos que para ellos resultan legítimos.

Lo anterior consolida la tesis según la cual la negación de la identidad discursiva y la desintegración de esa representación identitaria, como consecuencia del deterioro del sentido y del sin sentido, originan múltiples manifestaciones de violencia y criminalidad. Finalmente, es posible afirmar que los enunciados y las identidades discursivas de los criminales funcionan como indicios de sus estructuras mentales, de lo que acontece en su compleja dimensión corporal y de las razones históricas de la criminalidad en un país como Colombia.

75 Frank Periodista, "Entrevista a Popeye", acceso el 31 de octubre de 2021, https://www.youtube.com/ watch?v=5xqWULtL31Q.

76 Erich Fromm, El corazón del hombre (México: Fondo de Cultura Económica, 2007), 65. 


\section{Bibliografía}

Arévalo Viveros, Luis Fernando. "Négation de l'identité et destruction de l'autre dans Scorpio City (1998), Relato de un asesino (2002) et Satanás (2002) de Mario Mendoza (Colombie, 1964)”. Tesis doctorado. Université d’Aix Marseille, 2019.

Bajtín, Mijaíl. Estética de la creación verbal. México: Siglo XXI, 1982.

Boeree, George. "Psicología general: Trastornos disociativos". Acceso el 31 de octubre de 2021. http://www. psicologia-online.com/ebooks/general/trastornos-disociativos.html.

Charaudeau, Patrick. "Las emociones como efectos de discurso". Acceso el 31 de octubre de 2021. http://www. patrick-charaudeau.com/Las-emociones-como-efectos-de.html.

Contravía. "Confesiones de un exparamilitar". Acceso el 31 de octubre de 2021. https://www.youtube.com/ watch?v=TOFsMqEhDeQ.

Courtés, Joseph. Análisis semiótico del discurso: Del enunciado a la enunciación. Madrid: Gredos, 1997.

Clínica Universidad de Navarra. "Diccionario médico". Acceso el 31 de octubre de 2021. http://www.cun.es/ diccionario-medico/terminos/hipoestesia.

Cruz Niño. Esteban. Los monstruos en Colombia sí existen. Bogotá: Random House, 2013.

Eco, Umberto. Decir casi lo mismo: Experiencias de traducción. Barcelona: Lumen, 2008.

Fontanille, Jacques. Sémiotique et littérature: Essais de méthode. París: Presses universitaires de France, 1999.

Fontanille, Jacques. Semiótica del discurso. Lima: Fondo de Cultura Económica, 2001.

Fontanille, Jacques. Soma y sema: Figuras semióticas del cuerpo. Lima: Editorial Universidad de Lima, 2008.

Frank Periodista. "Entrevista a Popeye". Acceso el 31 de octubre de 2021. https://www.youtube.com/ watch? $=5 x q W U L t L 31 Q$

Freud, Sigmund. El malestar en la cultura. Madrid: Alianza, 2015.

Fromm, Erich. El corazón del hombre. México: Fondo de Cultura Económica, 2007.

Geertz, Clifford. La interpretación de las culturas. Barcelona: Gedisa, 1989.

Goffman, Erving. La presentación de la persona en la vida cotidiana. Buenos Aires: Amorrortu, 1997.

Greimas, Algirdas. Del sentido II. Madrid: Gredos, 1989.

Greimas, Algirdas y Courtés, Joseph. Diccionario razonado de la teoría del lenguaje. Volumen 1. Madrid: Gredos, 1990.

Greimas, Algirdas y Courtés, Joseph. Diccionario razonado de la teoría del lenguaje. Volumen II. Madrid: Gredos, 1991.

Greimas, Algirdas y Fontanille, Jacques. Semiótica de las pasiones: De los estados de cosas a los estados de ánimo. Madrid: Siglo XXI, 1994.

Landowski, Eric. “Tres regímenes de sentido y de interacción”. Tópicos del Seminario, n. ${ }^{\circ} 14$ (2005): 137-179.

Latella, Graciela. Metodología y teoría semiótica. Buenos Aires: Hachette, 1986.

Marina, José Antonio. La selva del lenguaje. Barcelona: Anagrama, 1998.

Mendoza, Mario. Scorpio City. Bogotá: Planeta, 1998.

Mendoza, Mario. Relato de un asesino. Bogotá: Planeta, 2001.

Mendoza, Mario. Satanás. Bogotá, Paneta, 2002.

Merleau-Ponty, Maurice. El ojo y el espíritu. Madrid: Trotta, 2013.

Noticias Caracol Televisión. "Andrés Leonardo Achipiz confesó haber asesinado a más de 30 personas". Acceso el 31 de octubre de 2021. https://www.youtube.com/watch?v=PW_a5hv_XP4.

Noticias Caracol. "Me poseyó una fuerza sobrenatural": alias el Desalmado confiesa crimen. Acceso el 31 de octubre de 2021. https://noticias.caracoltv.com/colombia/me-poseyo-una-fuerza-sobrenatural-alias-el-desalmado-confiesacrimen.

Rastier, François. Semántica interpretativa. México: Siglo XXI, 2005.

Ricœur, Paul. Tiempo y narración. Vol. 3: El tiempo narrado. México: Siglo XXI, 2003.

Ricœur, Paul. Sí mismo como otro. México: Siglo XXI, 1996.

Serrano Orejuela, Eduardo. "Narración, argumentación y construcción de identidad". En Didáctica del discurso. Editado por María Cristina Martínez, 9-104. Cali: Universidad del Valle, 2005.

Van Alphen, Ernest. "Experiencia, memoria y trauma: Síntomas de discursividad". En Trauma, cultura e historia: Reflexiones interdisciplinarias para el nuevo milenio. Editado por Francisco Ortega, 195-215. Bogotá: Universidad Nacional de Colombia, 2011. 